\title{
RGIM: An Integrated Approach to Improve QoS in AODV, DSR and DSDV Routing Protocols for FANETS using Chain Mobility Model
}

\author{
Parampreet Kaur $^{1}$, Ashima Singh ${ }^{1}$ and Sukhpal Singh Gill ${ }^{2}$ \\ ${ }^{1}$ Computer Science and Engineering Department \\ Thapar Institute of Engineering and Technology, Patiala, Punjab, India \\ ${ }^{2}$ School of Electronic Engineering and Computer Science \\ Queen Mary University of London, UK \\ parampreetkaur93@gmail.com, ashima@thapar.edu, s.s.gill@qmul.ac.uk
}

\begin{abstract}
Flying Ad-hoc Networks (FANETs) is a collection of Unmanned Aerial Vehicles (UAVs) that communicate without any predefined infrastructure. FANETs, being one of the most researched topics nowadays, finds its scope in many complex applications like drones used for military applications, border surveillance systems and other systems like civil applications in traffic monitoring and disaster management. Quality of Service (QoS) performance parameters for routing e.g. delay, Packet Delivery Ratio (PDR), jitter and throughput in FANETs are quite difficult to improve. Mobility models play an important role in evaluating the performance of the routing protocols. In this paper, the integration of two selected mobility models, i.e. Random Waypoint and Gauss-Markov Model is implemented. As a result, Random Gauss Integrated Model (RGIM) is proposed for evaluating the performance of AODV (Ad hoc On-demand Distance Vector), DSR (Dynamic Source Routing) and DSDV (Destination-Sequenced Distance-Vector) routing protocols. The simulation is done with NS2 simulator for various scenarios by varying the number of nodes and taking low and high node speed 50 and 500 respectively. The experimental results show that the proposed model improves the QoS performance parameters of AODV, DSR and DSDV protocol.
\end{abstract}

Keywords: FANETs · Random Waypoint Model · Gauss-Markov Model · Routing Protocols · QoS parameters

\section{Introduction}

Flying Ad-hoc Networks (FANETs) represent a special kind of mobile ad-hoc network. In FANETs, the ad-hoc network is between Unmanned Aerial Vehicles (UAVs), which fly independently without carrying any human pilot. All the UAVs form an ad-hoc network, but the only subset of UAVs communicates with the base station or satellite as shown in Figure 1 [1]. UAVs are used in various applications like emergency support, border surveillance, disaster monitoring and rescue operations [2-4]. In comparison to other Ad-hoc networks, change in the node's mobility in FANETs is considerably high and change in topology is also very frequent [5]. Mobility models are used to develop these mobility scenarios in the wireless ad-hoc network and different routing protocols are implemented using various mobility scenarios. In FANETs, the routing protocols are categorized as topology-based, swarm-based and position-based. In topology-based routing, the various protocols proposed as proactive are: OLSR (Optimized Link State Routing), DSDV (Destination-Sequenced Distance-Vector); as reactive are: AODV (Ad hoc On-demand Distance Vector) and DSR (Dynamic Source Routing); and as hybrid are: HWMP (Hybrid Wireless Mesh Protocol), HRPO (Hierarchical Routing Protocol), ZRP (Zone Routing Protocol) and TORA (Temporarily Ordered Routing Algorithm) [6]. In swarm-based routing, the proposed protocols are: APAR (Ant colony optimization-based Polymorphism-Aware Routing) and Bee Adhoc. The position-based routing has protocols categorized on single-path are: GLSR (Geographic Load Share Routing), MPGR (Mobility Prediction Geographic Routing), LAROD (Location Aware Routing for Delay tolerant networks), GRAA (Geographic Routing protocol for Aircraft Ad hoc Network), UVAR (UAV-Assisted VANET Routing Protocol), P-OLSR (Position-based OLSR); and others based on multipath are: ARPAM (Ad-hoc Routing Protocol for Aeronautical Mobile Ad-hoc Networks), RGR (Reactive Greedy Reactive), PASER (Position Aware Secure and Efficient Mesh Routing), LCAD (Load Carry and Deliver Routing) [6]. The mobility models for FANETs are Random waypoint mobility model, Random movements, Gauss-Markov, Pheromone repel, Semi-Random Circular Movement, Paparazzi mobility model [6]. 


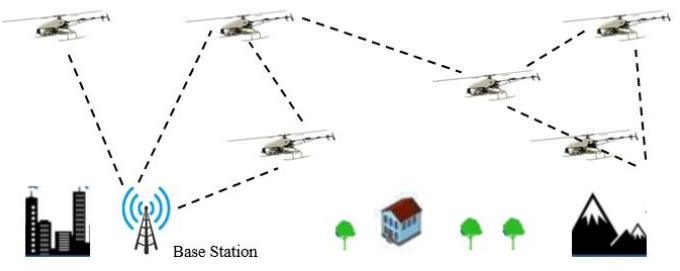

\subsection{Our Contributions}

Figure 1. Flying Ad-hoc Network [1]

The Quality of Service (QoS) parameters that are considered for effective routing in FANETs demand delay and jitter to be minimized whereas the Packet Delivery Ratio (PDR) and throughput to be increased. In the wireless adhoc network, the chain mobility model is formed by integrating Manhattan Grid model and Random waypoint model $[7,8]$. This motivates to propose a new chain mobility model i.e. RGIM (Random Gauss Integrated Model) using existing models with a specific goal to improve the performance of routing protocols.

The main objective is to identify the existing mobility models that can be integrated to form a chain. In FANETs, the QoS parameters are mostly evaluated by using Random waypoint $[9,10]$ and Gauss-Markov model $[11,12]$. These two models are selected to form a chain as they are widely accepted to evaluate the QoS parameters for FANETs. In this paper, a new chain mobility model combining Random Waypoint and Gauss-Markov is proposed for better performance of FANETs routing protocols. The proposed chain mobility model creates mobility scenarios using BonnMotion [13] and is simulated using the NS2 simulator [14]. The purpose of this work is to optimize delay, PDR, jitter and throughput for AODV, DSR and DSDV protocols in FANETs.

The paper is organized as follows. Section 2 presents existing mobility models and the related work. The proposed chain model is described in Section 3. Section 4 discusses the implementation details and presents the experimental results. The conclusions and future scope are presented in Section 5.

\section{Related Work}

Mobility model is devised to define the movement pattern of a node and it also represents how the node changes its location, acceleration, and velocity over time [35]. A realistic simulation environment created using mobility model, plays a major role to evaluate various ad-hoc routing protocol's performance [36]. The performance of protocols varies significantly by applying diverse mobility models. The routing protocol performance is analyzed by using various mobility models as covered in the literature.

The Random Waypoint mobility model is used to perform simulations in the ad-hoc network for various routing protocols given by following authors: P. Sharma and I. Yadav [15] performed simulation in improving ReactiveGreedy-Reactive (RGR) protocol under Random Waypoint model over a FANET network. The results show that RGR protocol gives better performance for the like metrics delay and throughput in comparison with original RGR and AODV protocol. Alexey V. Leonov [9] experimentally analyzed AntHocNet and BeeAdHoc protocols to provide a solution to the problem of routing in FANETs. The simulation is done under Random Waypoint model using NS-2 simulator. The performance of protocols is examined using throughput, delay and routing overhead parameters. The results show that AntHocNet and BeeAdHoc are more efficient when compared with AODV, DSDV and DSR protocols. G. Gankhuyag et al. [16] proposed a novel directional hybrid routing scheme with enhancement of the AODV routing protocol for FANETs. The proposed hybrid routing uses both unicast and geocast routing. The proposed routing is compared with the traditional AODV routing by applying the Random Waypoint model for success of route setup and lifetime of active path. The results show that the enhanced AODV routing performs better than traditional AODV. J. M. M. Biomo et al. [10] optimized the RGR routing protocol for a recovery strategy in Unmanned Aerial Ad-hoc network. The performance is evaluated using OPNET under Random Waypoint model for PDR, delay, and control overhead. The results show that optimized RGR performs better for packet delivery ratio when compared to modified RGR. P. Gupta and S. Gupta [17] evaluated the mobility effect on 
the AODV, DSDV, OLSR and DSR performance with Random Waypoint model. The simulation is done using the NS2 simulator to get PDR, delay and routing load. The results show that AODV gives better performance in comparison with other protocols. A. Kout et al. [18] defined AODVCS, a protocol based on cuckoo search method in MANETs. AODVCS is implemented with NS2 using Random waypoint model. The comparison of AODVCS is done with AODV, DSDV, and AntHocNet for PDR and delay. From the result, AODVCS is considered better in terms of PDR and delay. Z. Zheng et al. [19] proposed hybrid communication protocol i.e. PPMAC (Position Prediction based directional MAC protocol) and RLSRP (Self-learning Routing Protocol based on Reinforcement Learning). The proposed protocols are implemented using MATLAB and NS2 with random waypoint mobility model and provide an intelligent communication in FANETs. G. Gankhuyag et al. [20] proposed a routing scheme with directional and dynamic angle adjustment for FANETs. The simulation is done using $\mathrm{C}++$ to evaluate route setup success and data delivery ratio. From the outcomes, it is concluded that the proposed scheme performs superior to AODV scheme.

The Gauss-Markov mobility model is used to perform the simulation of various routing protocols given by following authors: J. M. M. Biomo et al. [11] proposed Enhanced Gauss-Markov (EGM) model for UAVs. The EGM model eliminates rapid pause and quick turning of mobile vehicles. The OPNET simulator is used to evaluate the performance in terms of PDR. The results show that EGM produces significantly more network partitions in comparison with Random Waypoint model. Lin Lin et al. [12] proposed MPGR protocol for ad-hoc UAVs. The results obtained from simulation using the Gauss model show that MPGR performs superior than AODV and GPSR (Greedy Perimeter Stateless Routing) for PDR and delay. D. Chenghao [21] improved DSR protocol with Gauss Markov model for reducing the impact of node movements in the simulation area. The results calculated using Qualnet shows an improvement in the improved DSR routing protocol's performance for PDR, throughput, delay, and jitter when compared with the original DSR routing protocol. M. Alenazi and C. Sahin [22] modified the implementation of 3D Gauss Markov model. The results show that mobile nodes follow smooth movements in an improved model by avoiding reaching the boundaries of simulation area. W. Jung et al. [23] proposed QGeo routing protocol for unmanned robotic networks. The simulation is done using NS-3 simulator with Gaussian Markov model. In results, QGeo performs better as compared to GPSR and QGrid for PDR and network overhead. W. Wang et al. [24] presented Semi-Random Circular Movement (SCRM) model for UAVs in MANETs. The simulation is done using NS2 simulator. The SRCM model performs better as compared to existing Random waypoint model in MANETs for the curved movement scenarios. N. E. H. Bahloul et al. [25] proposed BR-AODV, flocking based protocol for routing purposes of UAVs. In proposed protocol, AODV is used for on-demand routing and Boids of Reynolds (BR) mechanism is used for route connection and maintenance for dynamic topology. The simulation is done using NS2 simulator and results show that BR-AODV performs better than AODV for throughput, delay and packet loss parameters.

The chain mobility model is proposed and used in the simulation of routing protocols by A. Bhasin and D. Kumar [7] and evaluated the DSR and AODV protocols performance using chain mobility model. The simulation is done using NS-2 to evaluate throughput, PDR and delay performance parameters. AODV and DSR give equal throughput using chain test random and chain campus model. In the chain test random model, DSR protocol results in more delay as compared to AODV. AODV gives a steady packet delivery ratio using a chain campus model and also packet delivery ratio of DSR is reduced. A. K. Shukla and C. K. Jha [8] compared chain mobility model (Manhattan Grid model and Random Waypoint model) with Random Waypoint model. The various parameters like throughput, delay and PDR are evaluated for DSR routing protocol. The simulation is done using NS-2 simulator. The results show that chain model gives better performance compared to the Random Waypoint mobility model. Y. Huan et al. [26] compared the performance of Reference point group mobility model, Random Waypoint, Manhattan and Freeway models for sparse networks. From the simulation, it is concluded that these four models are not relevant for a sparse network. Therefore, the authors proposed a chain mobility model for efficient communication between nodes, which performed better in a sparse network. Table 1 compares the proposed model RGIM with routing protocols using existing mobility models. In these research works, the chain mobility model is formed by integrating Random Waypoint and Manhattan Grid model, but no chain model is formed with Random Waypoint and GaussMarkov model. 
Table 1 Comparison of RGIM with existing mobility models

\begin{tabular}{|c|c|c|c|c|c|c|}
\hline Technique & $\begin{array}{c}\text { Mobility } \\
\text { model }\end{array}$ & $\begin{array}{c}\text { Adhoc } \\
\text { Network }\end{array}$ & Simulator & $\begin{array}{c}\text { QoS } \\
\text { parameters }\end{array}$ & $\begin{array}{l}\text { Routing } \\
\text { protocols }\end{array}$ & Result \\
\hline $\begin{array}{l}\text { Improved } \\
\text { RGR [15] }\end{array}$ & $\begin{array}{l}\text { Random } \\
\text { waypoint }\end{array}$ & FANET & NS2 & Delay, throughput & AODV, RGR & $\begin{array}{l}\text { RGR perform better for the } \\
\text { delay and throughput }\end{array}$ \\
\hline $\begin{array}{l}\text { AntHocNet } \\
\text { and } \\
\text { BeeAdHoc [9] }\end{array}$ & $\begin{array}{l}\text { Random } \\
\text { waypoint }\end{array}$ & FANET & NS2 & $\begin{array}{l}\text { Throughput, } \\
\text { routing overhead } \\
\text { and delay }\end{array}$ & $\begin{array}{l}\text { AODV, DSR, } \\
\text { DSDV, } \\
\text { BeeAdHoc, and } \\
\text { AntHocNet }\end{array}$ & $\begin{array}{l}\text { AntHocNet and BeeAdHoc } \\
\text { are more efficient }\end{array}$ \\
\hline $\begin{array}{l}\text { Enhanced } \\
\text { AODV [16] }\end{array}$ & $\begin{array}{l}\text { Random } \\
\text { waypoint }\end{array}$ & FANET & $\begin{array}{l}\text { Programmin } \\
\mathrm{g} \quad \text { language } \\
(\mathrm{C}++)\end{array}$ & $\begin{array}{l}\text { Route setup and } \\
\text { lifetime of an } \\
\text { active path }\end{array}$ & AODV & $\begin{array}{lrr}\text { Enhanced } & \text { AODV } & \text { routing } \\
\text { performs } & \text { better } & \text { than } \\
\text { traditional AODV } & \end{array}$ \\
\hline RGR [10] & $\begin{array}{l}\text { Random } \\
\text { waypoint }\end{array}$ & $\begin{array}{l}\text { Unmanned } \\
\text { Aerial Ad-hoc } \\
\text { Network }\end{array}$ & OPNET & $\begin{array}{l}\text { PDR, delay and } \\
\text { control overhead }\end{array}$ & RGR & 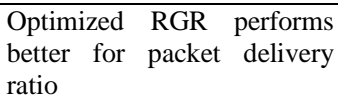 \\
\hline $\begin{array}{l}\text { AODV, } \\
\text { DSDV, OLSR } \\
\text { and DSR [17] }\end{array}$ & $\begin{array}{l}\text { Random } \\
\text { waypoint }\end{array}$ & MANET & NS2 & $\begin{array}{l}\text { Routing load, } \\
\text { delay, and PDR }\end{array}$ & $\begin{array}{lr}\text { AODV, } & \text { DSR, } \\
\text { OLSR, } & \text { and } \\
\text { DSDV } & \end{array}$ & $\begin{array}{l}\text { AODV give better } \\
\text { performance compared to } \\
\text { other protocols }\end{array}$ \\
\hline EGM [11] & $\begin{array}{l}\text { Enhanced Gauss- } \\
\text { Markov, Random } \\
\text { waypoint }\end{array}$ & $\begin{array}{l}\text { Unmanned } \\
\text { Aerial } \\
\text { Vehicles }\end{array}$ & OPNET & PDR & $\begin{array}{l}\text { Optimized- } \\
\text { RGR }\end{array}$ & $\begin{array}{l}\text { EGM produces a large } \\
\text { number of network partitions } \\
\text { compared to the Random } \\
\text { Waypoint }\end{array}$ \\
\hline MPGR [12] & $\begin{array}{ll}\begin{array}{l}\text { Gauss } \\
\text { model }\end{array} & \text { mobility }\end{array}$ & UAVs & - & Delay and PDR & $\begin{array}{l}\text { MPGR, AODV, } \\
\text { and GPSR }\end{array}$ & $\begin{array}{l}\text { MPGR outperforms AODV } \\
\text { and GPSR }\end{array}$ \\
\hline $\begin{array}{l}\text { Improved } \\
\text { DSR [21] }\end{array}$ & $\begin{array}{l}\text { Gauss Markov } \\
\text { mobility model }\end{array}$ & $\begin{array}{l}\text { Adhoc } \\
\text { Network }\end{array}$ & Qualnet & $\begin{array}{l}\text { Packet delivery } \\
\text { ratio, throughput, } \\
\text { delay and jitter }\end{array}$ & DSR & $\begin{array}{l}\text { Improvement in performance } \\
\text { of improved DSR routing } \\
\text { protocol }\end{array}$ \\
\hline SRCM [24] & $\begin{array}{l}\text { semi-random } \\
\text { circular } \\
\text { movement, } \\
\text { Random } \\
\text { waypoint }\end{array}$ & MANET & NS2 & $\begin{array}{l}\text { Node } \\
\text { distribution }\end{array}$ & - & $\begin{array}{l}\text { SRCM outperforms Random } \\
\text { waypoint }\end{array}$ \\
\hline $\begin{array}{ll}\text { AODV, } & \text { DSR } \\
{[7]} & \end{array}$ & $\begin{array}{l}\text { Chain model } \\
\text { (Random } \\
\text { Waypoint, } \\
\text { Manhattan) }\end{array}$ & MANET & NS2 & $\begin{array}{l}\text { Throughput, PDR, } \\
\text { delay }\end{array}$ & AODV, DSR & $\begin{array}{l}\text { AODV gives a steady PDR, } \\
\text { and PDR of DSR is reduced }\end{array}$ \\
\hline DSR [8] & $\begin{array}{l}\text { Chain model } \\
\text { (Random } \\
\text { Waypoint, } \\
\text { Manhattan Grid) }\end{array}$ & $\begin{array}{l}\text { Adhoc } \\
\text { Network }\end{array}$ & NS2 & $\begin{array}{l}\text { Throughput, End } \\
\text { to End delay, } \\
\text { Packet Delivery } \\
\text { Ratio }\end{array}$ & DSR & $\begin{array}{l}\text { Chain model gives better } \\
\text { performance compared to the } \\
\text { Random Waypoint mobility } \\
\text { model }\end{array}$ \\
\hline $\begin{array}{l}\text { RGIM (this } \\
\text { work) }\end{array}$ & $\begin{array}{l}\text { Random } \\
\text { Waypoint and } \\
\text { Gauss-Markov }\end{array}$ & FANET & NS2 & $\begin{array}{l}\text { PDR, End to End } \\
\text { delay, Throughput, } \\
\text { Jitter }\end{array}$ & $\begin{array}{l}\text { AODV, DSR, } \\
\text { DSDV }\end{array}$ & $\begin{array}{l}\text { RGIM gives more packet } \\
\text { delivery ratio, less end to end } \\
\text { delay, less jitter and better } \\
\text { throughput than individual } \\
\text { Random Waypoint and } \\
\text { Gauss-Markov mobility } \\
\text { model }\end{array}$ \\
\hline
\end{tabular}




\section{RGIM: The Proposed Chain Mobility Model}

To analyze routing protocol performance in FANET, a new chain model is proposed. The proposed model is formed by integrating two mobility models, i.e. Random waypoint and Gauss-Markov. In the proposed chain mobility model, the Random Waypoint and Gauss-Markov are selected for integration because existing research finds huge acceptance and usage of these two mobility models for simulation of routing protocols in FANETs [5, 9, 10, 11 12, 15 and 16]. Random waypoint model allows nodes to move randomly in any direction with random speed within the simulation area. Using this model, the nodes decide their movement based on fixed probabilities. This model uses pause time before changing the node speed or direction. The Random Waypoint Model is one of the simplest and easiest models to use. In Gauss-Markov model, every node is given a particular speed and direction at starting which is updated at a fixed interval of time. It states that the speed and direction at some instance $\left(\mathrm{n}^{\text {th }}\right)$ of time depends upon previous instance $\left(n-1^{\text {th }}\right)$ of time.

\subsection{Problem formulation}

To improve various Quality of Service (QoS) performance parameters like delay, PDR, jitter and throughput are the main areas of concern in FANETs. Mobility model is used to evaluate the performance of the routing protocols in the wireless ad-hoc network. The purpose of this work is to implement an effective mobility model using chaining of selected mobility models, i.e. Random Waypoint and Gauss-Markov to improve various QoS parameters i.e. Packet delivery ratio, throughput, jitter and delay of AODV, DSR and DSDV protocols.

\subsection{QoS Parameters}

In FANETs, the main objective is to minimize the delay and jitter, maximize PDR and throughput. The proposed chain mobility model will help in improving these QoS parameters such as PDR, delay, jitter and throughput. PDR is the ratio between the received packets at the destination and the sent packets from the source as found in the trace file. For the calculation of PDR, the formula is given as Eq. 1. End to End Delay is the average time taken to reach the destination by a sent data packet and is represented in milliseconds (ms). For the calculation of end to end delay, the formula is as given in Eq. 2. Jitter is the time variation in received packets at destination because of topology change and network congestion. Throughput is the rate of successfully received packets and is represented in kbps. Throughput is calculated by using the following formula in Eq. 3.

$$
\begin{gathered}
\text { PDR }=\frac{\text { Total number of received packets }}{\text { Total number of sent packets }} \\
\text { Delay }=\frac{\text { Packet arrive time-Packet sent time }}{\text { Number of connections }} \\
\text { Throughput }=\frac{\text { Received packets }}{\text { Transmission period }}
\end{gathered}
$$

\subsection{Random Gauss Integrated Model (RGIM)}

The proposed model is a combination of two mobility models: Random waypoint, Gauss-Markov. In FANET, at starting the movement of UAVs will be modeled according to Random Waypoint model and when the UAVs are near their destination, the movement is modeled by Gauss-Markov model. Firstly, the mobility scenario of nodes is created using the Random Waypoint model and Gauss-Markov model separately for the same number of nodes with Bonnmotion. In the next step, both the created scenarios are integrated with the help of chain model. 


\subsubsection{Random Waypoint Model (RWPM)}

The model uses the pause time before changing the speed or direction of a node. The nodes are free to move randomly with any speed in any direction within the simulation area for this model. Figure 2 shows the node movement in random waypoint model. In FANET, the UAVs that move randomly in this model decide their action on the basis of fixed probabilities. This mobility model depends on three activities: "go straight", "turn left" and "turn right" [27]. The algorithm of the Random Waypoint model [28] is explained below.

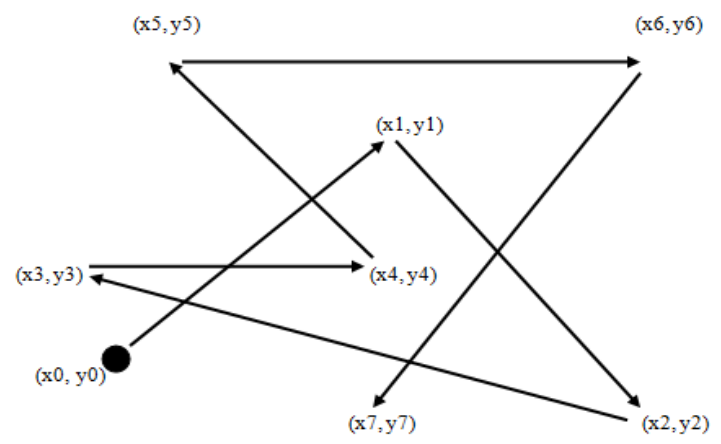

Figure 2. Node movement in random waypoint model [29]

\section{Algorithm 1: Random Waypoint Model (RWPM)}

Input: Movement duration parameter of node (i), identification parameter of node (j), speed of node (V), movement vector (P), pause time (T) Output: Movement of node

Begin

1. For each node do

2. Assign $\mathrm{i}=$ movement duration, $\mathrm{j}=$ identification of node

3. Set vector $P_{i}^{(j)}=$ random waypoint

4. $\left\{P_{i}^{(j)}\right\}_{i \in N_{0}}=P_{0}^{(j)}, P_{1}^{(j)}, P_{2}^{(j)}, P_{3}^{(j)}$ $[28]$

(3.1) //represent movement traces of a node in the model

5. Select $V_{i}$ from $\left\{P_{i-1}-P_{i}\right\}$

6. Set $T_{p, i}$ at $P_{i}$

7. $\left\{\left(P_{i}, V_{i}, T_{p, i}\right)\right\}_{i \in N}=\left(P_{1}, V_{1}, T_{p, 1}\right),\left(P_{2}, V_{2}, T_{p, 2}\right),\left(P_{3}, V_{3}, T_{p, 3}\right), .$. [28]

8. end for each End

\subsubsection{Gauss-Markov Model (GMM)}

In this model, each mobile node is initialized with a particular speed and direction, which is updated after a fixed interval of time. To be precise, the node direction and speed value at the $\mathrm{n}^{\text {th }}$ instance of time is computed on the basis of value at the $n-1^{\text {st }}$ instance of time. This model is used for the simulation of UAVs behavior in a swarm. Figure 3 shows the movement of nodes in Gauss-Markov model as per earlier node position. The algorithm of Gauss-Markov model [30] is explained below: 


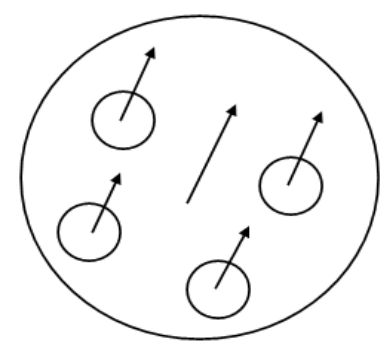

Figure 3. Node movement in Gauss-Markov model [29]

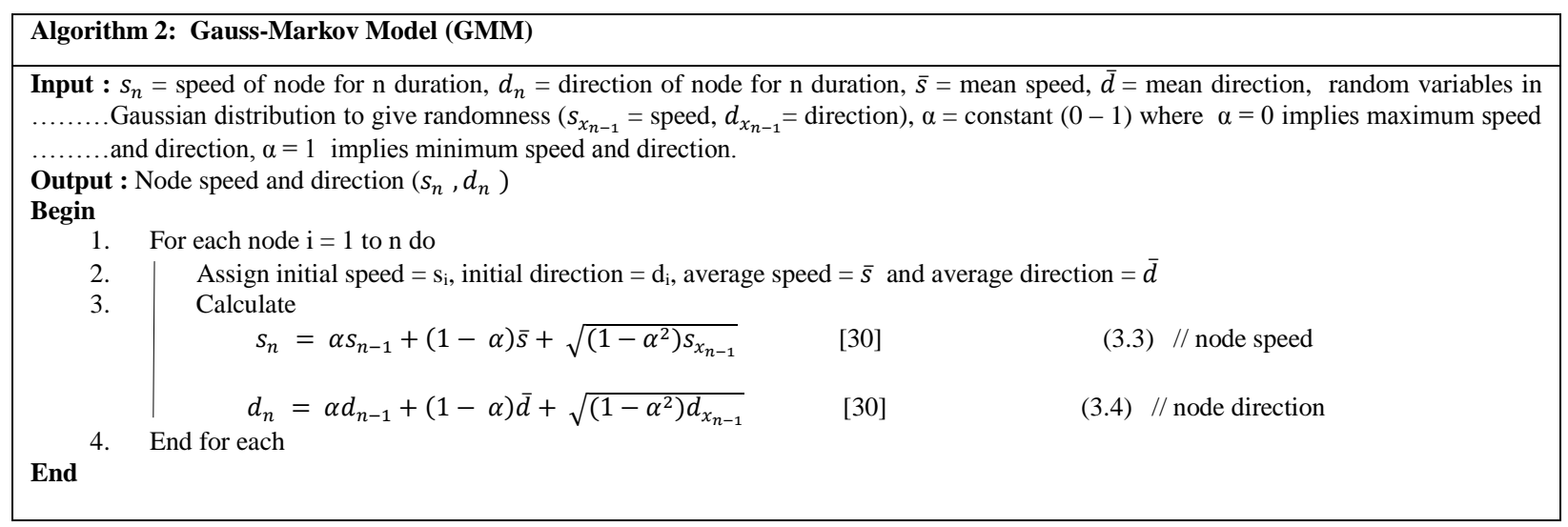

\subsubsection{Chain Mobility Model}

The chain model is a concatenation of various mobility models (Random Waypoint, Reference Point Group Mobility model, Manhattan Grid, Gauss-Markov). For chaining, the node's last position of $n-1^{\text {th }}$ scenario is joined with the first position of $n^{\text {th }}$ scenario. In this paper, the chain model is formed by connecting last position of $n-1^{\text {th }}$ scenario (Random Waypoint model) with the first position of $n^{\text {th }}$ scenario (Gauss-Markov model). The chain scenario generated is integration of Random Waypoint model and Gauss-Markov model, having duration value equal to sum of duration of both models, number of nodes will be equal to nodes in any of the model used. The duration of the simulation done is $500 \mathrm{~s}$. For $0 \mathrm{~s}$ to $250 \mathrm{~s}$ nodes move with Random Waypoint model and for next $250 \mathrm{~s}$ the nodes move with Gauss-Markov model. The proposed chain model, i.e. RGIM is formed only if the nodes of both scenarios, i.e. Random Waypoint and Gauss-Markov are equal, and the simulation area of the first scenario is within the scope of the second scenario. If these conditions are satisfied, the chain model has generated otherwise the generation fails. The proposed algorithm of chain mobility model is represented by an activity diagram as given below in Figure 4. The proposed RGIM is described in algorithm 3 as given below. 


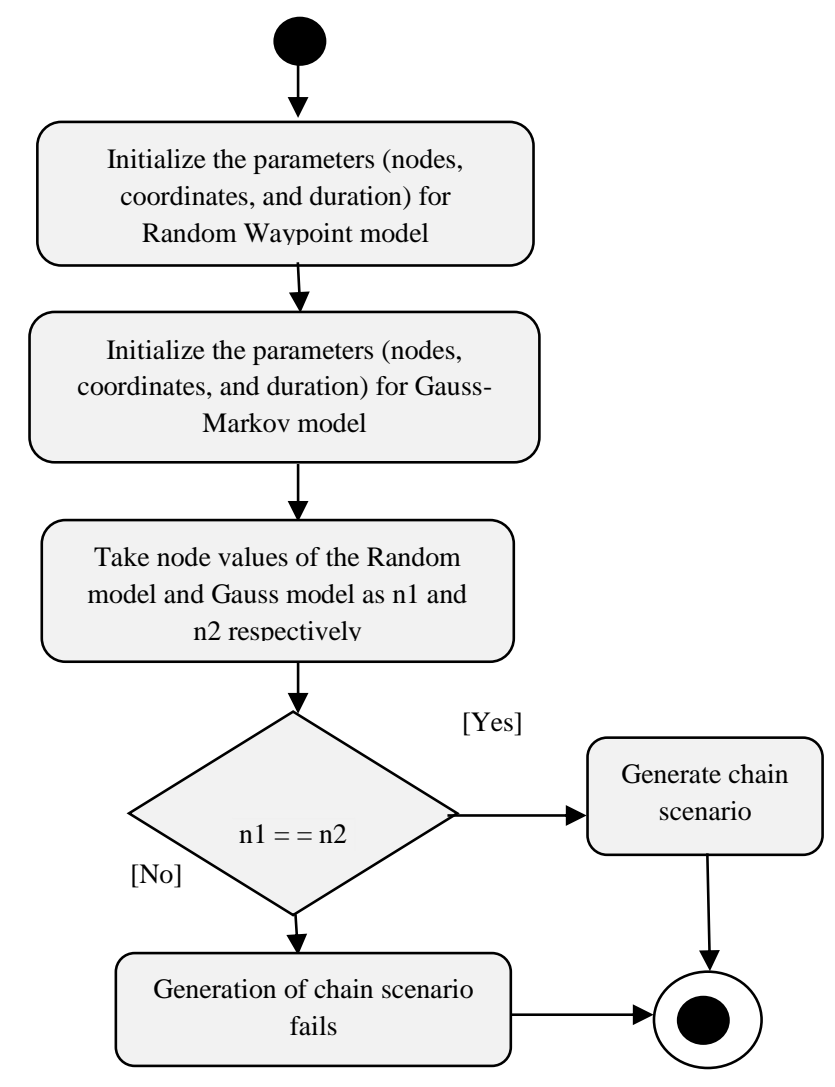

Figure 4 Activity diagram showing proposed chain mobility model

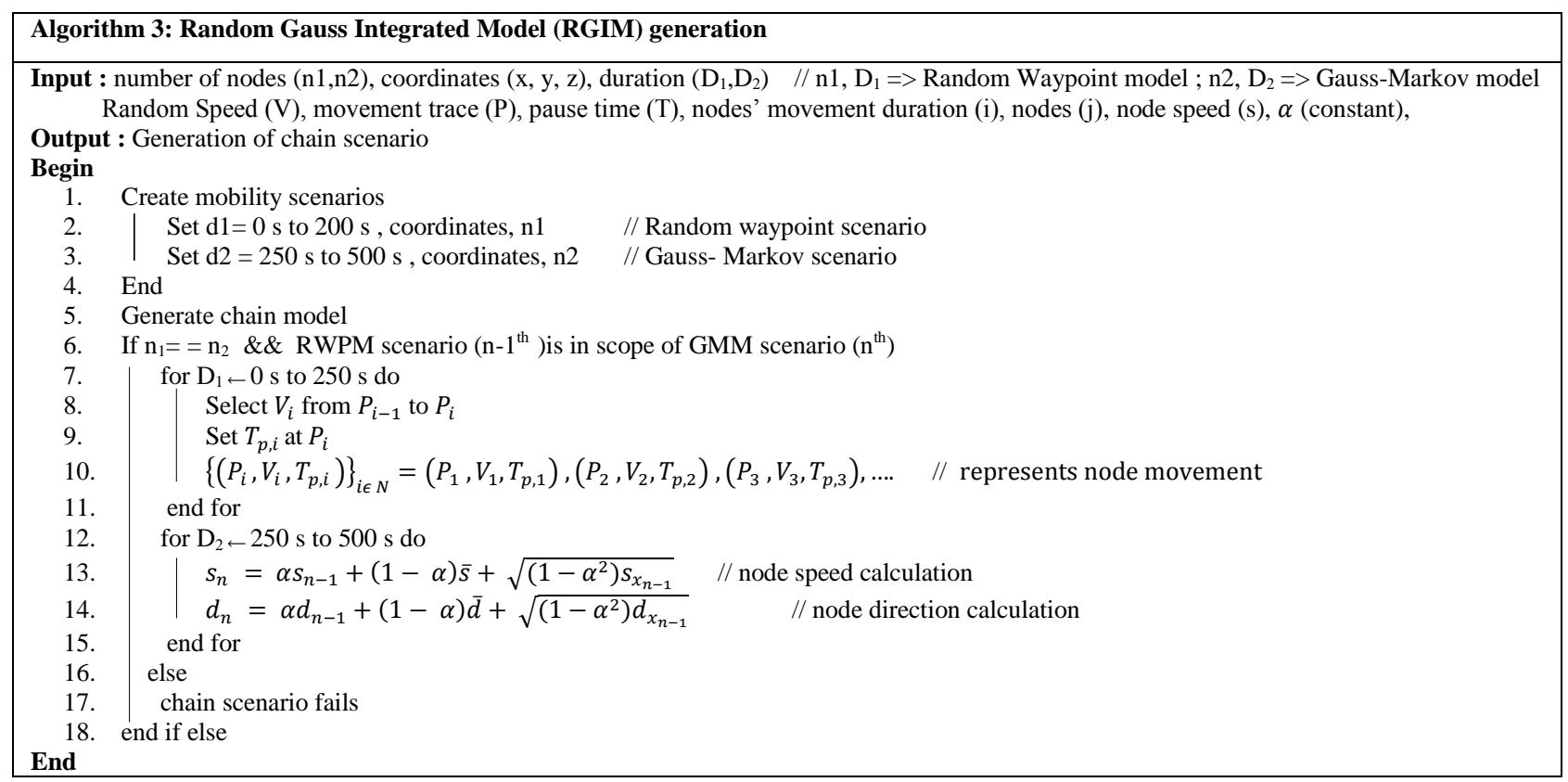




\section{Implementation and Experimental Results}

In this section, we implemented our proposed chain model, i.e. RGIM, to know its effectiveness in various QoS performance parameters. Firstly, the simulation parameters are defined and then RGIM is compared with the Random waypoint, Gauss-Markov models in terms of PDR, delay, jitter and throughput.

\subsection{Implementation details}

The proposed model is implemented in the NS-2 simulator [14] using various simulation parameters to evaluate the results on different performance parameters.

\subsubsection{Simulation Platform}

The NS-2 simulator [14] is used to calculate and analyze the performance of AODV, DSR, DSDV with various mobility models. NS-2 is an event-driven simulation tool used to simulate the wired and wireless network protocols. NS-2 uses C++ language at backend and $\mathrm{OTcl}$ at the front-end.

\subsubsection{Simulation Parameters}

The various parameters for simulation are described in Table 2. In simulation, high dynamic scenario having frequent topology changes [31] [33] [34] is generated by using pause time i.e. 10 seconds.

Table 2. Simulation Parameters

\begin{tabular}{ll}
\hline Parameter & Value \\
\hline Simulator & NS-2 (Version-2.35) \\
Channel Type & Channel/Wireless Channel \\
Protocol & AODV, DSR, DSDV \\
Mobility Models & $\begin{array}{l}\text { Random Waypoint, } \\
\text { Gauss-Markov, Chain } \\
\text { Mobility Model }\end{array}$ \\
Traffic Type & TCP \\
MAC Layer Protocol & 802.11 \\
Number of Nodes per & 10,50 \\
Simulation & \\
Node speed & $50 \mathrm{~m} / \mathrm{s}, 500 \mathrm{~m} / \mathrm{s}$ \\
\hline
\end{tabular}

\subsubsection{Performance Parameters}

Three performance parameters, i.e., Packet Delivery Ratio, Throughput, Jitter and Average End to End Delay are used to analyze AODV, DSR, DSDV performance with different Mobility Models. 


\subsection{Experiential Results and Analysis}

In the simulation, AODV, DSR and DSDV routing protocol have been analyzed with different mobility models (RWPM, GMM, RGIM) for varying number of nodes $(10,50)$ and varying speed of nodes $(50 \mathrm{~m} / \mathrm{s}, 500 \mathrm{~m} / \mathrm{s})$. The results of the simulation are obtained from the generated trace files using AWK scripts.

\subsubsection{Simulation Results of AODV routing protocol with different mobility models}

\section{Test Case 1: PDR}

Figure 5 represents the variation of packet delivery ratio due to change in the number and speed of nodes for AODV protocol using different mobility models (Random Waypoint, Gauss-Markov, and RGIM). The graph represents that the AODV with RGIM gives increase in packet delivery ratio values as compared to RWPM and GMM.

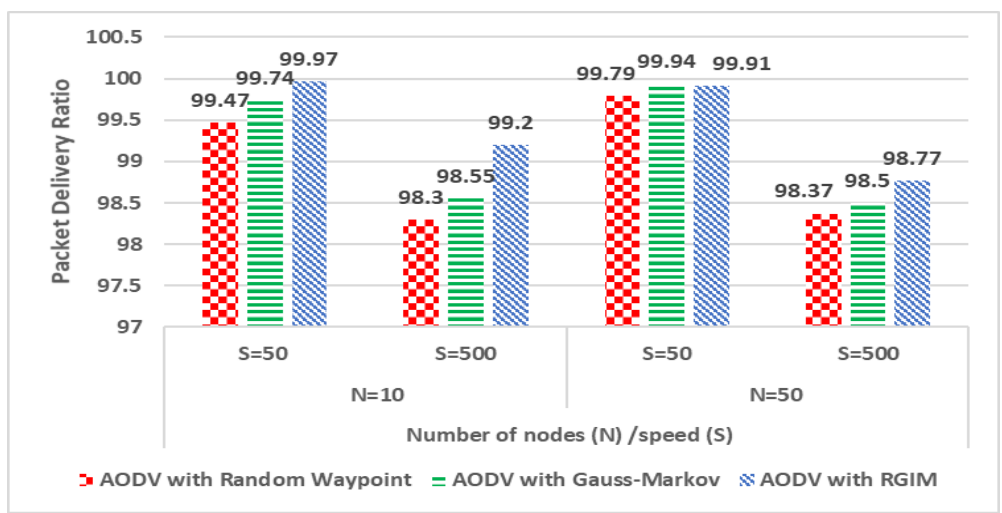

Figure 5 Number/speed of nodes vs. PDR for AODV

\section{Test Case 2: End to End delay}

Figure 6 presents the variation in the end to end delay due to change in the number and speed of nodes for AODV routing protocol using different mobility models (Random Waypoint, Gauss-Markov, and RGIM). From the graph, it is clear that AODV with RGIM gives decline in delay values in comparison with RWPM and GMM.

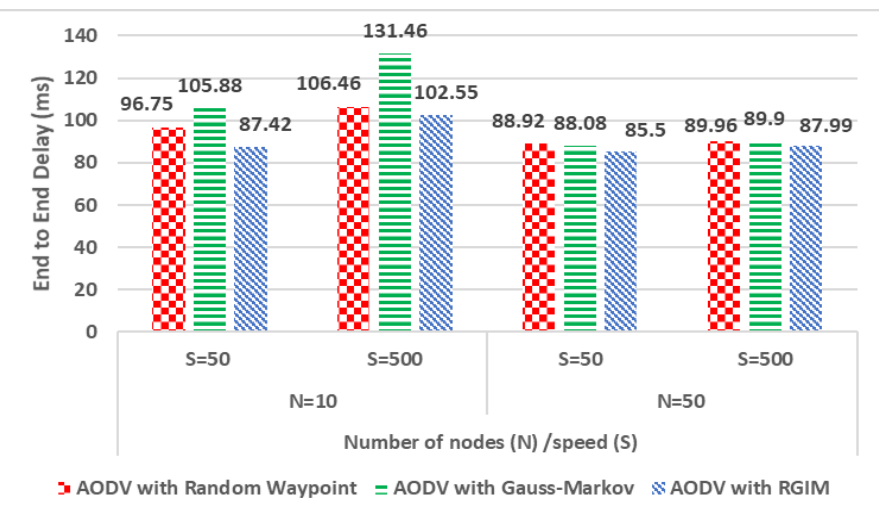

Figure 6 Number/speed of nodes vs. End to End delay for AODV 


\section{Test Case 3: Throughput}

Figure 7 displays the variation of throughput of the AODV routing protocol with the change in the number and speed of nodes using different mobility models (Random Waypoint, Gauss-Markov, and RGIM). The graph shows that the AODV with RGIM gives increase in throughput values as compared to RWPM and GMM.

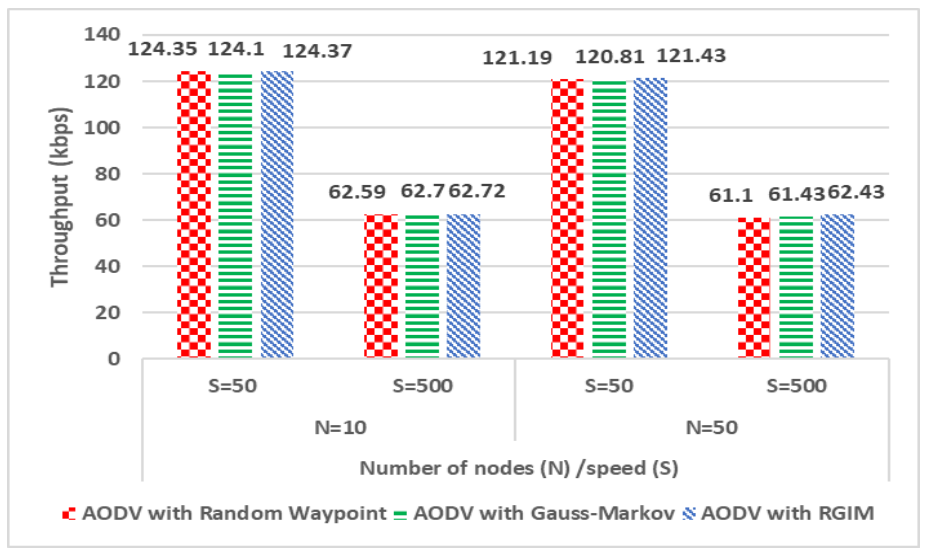

Figure 7 Number/speed of nodes vs. Throughput for AODV

\section{Test Case 4: Jitter}

Figure 8 displays the variation of jitter of the AODV routing protocol with the change in the number and speed of nodes using different mobility models (Random Waypoint, Gauss-Markov, and RGIM). The graph shows that the AODV with RGIM gives decrease in jitter values as compared to RWPM and GMM.

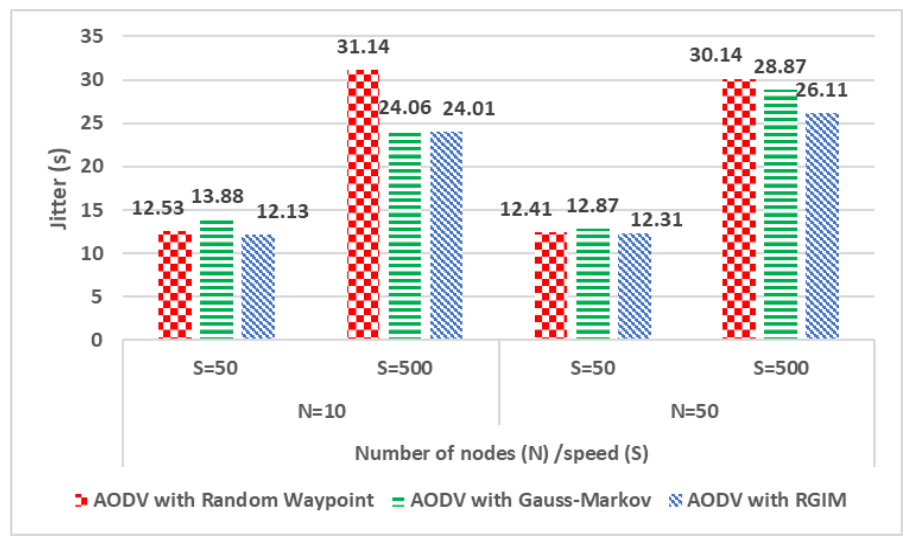

Figure 8 Number/speed of nodes vs. Jitter for AODV

\subsubsection{Simulation analysis of AODV}

From Figure 5, it is observed that for 10 and 50 number of nodes, with high speed of nodes i.e. $500 \mathrm{~m} / \mathrm{s}$, there is decrease in PDR. In RGIM, there is increase in PDR compared to RWPM and GMM. The increase in PDR is not much significant, but the minor increase is there because of less link interruption in RGIM. From Figure 6, it is observed that for 10 and 50 number of nodes, with high node speed of $500 \mathrm{~m} / \mathrm{s}$ the delay values increase. In RGIM, there is significant decrease in end to end delay compared to RWPM and GMM. The decrease in delay occurs because the proposed model makes more stable links during communication. From Figure 7, it is observed that for 10 and 50 number of nodes, as speed of node is high i.e. $500 \mathrm{~m} / \mathrm{s}$, there is significant decrease in throughput values. The model RGIM shows minor increase in throughput compared to RWPM and GMM. There is high throughput for 
speed $50 \mathrm{~m} / \mathrm{s}$, as the models works better for low node speed in the simulation. From Figure 8, it is observed that for 10 and 50 number of nodes, with high node speed of $500 \mathrm{~m} / \mathrm{s}$, the jitter value increases. The model RGIM shows decrease in jitter compared to RWPM and GMM.

\subsubsection{Simulation Results of DSR routing protocol with different mobility models}

\section{Test Case 1: PDR}

Figure 9 displays the variation of the PDR of DSR routing protocol with the change in the number and speed of nodes using different mobility models (Random Waypoint, Gauss-Markov, and RGIM). The graph shows that the DSR with RGIM gives increase in packet delivery ratio values as compared to RWPM and GMM.

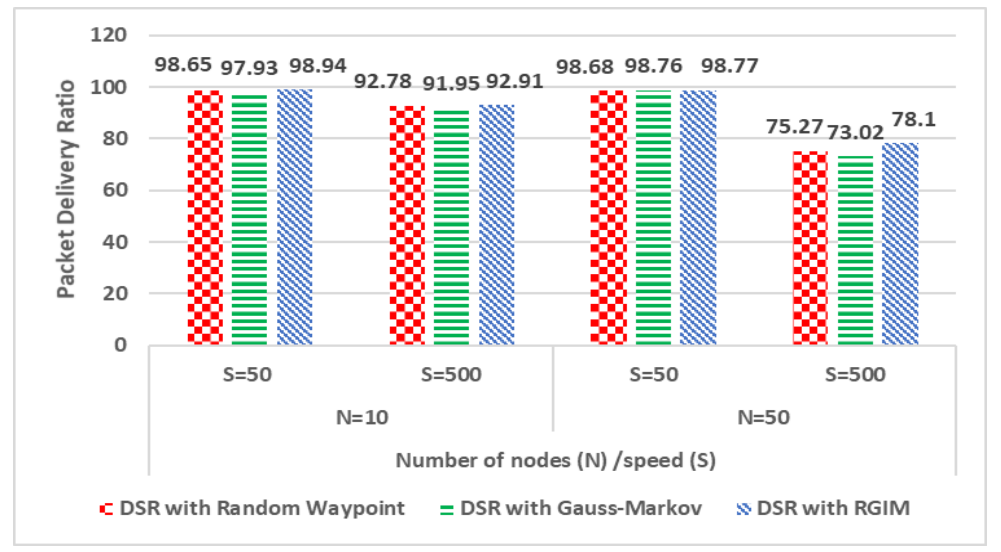

Figure 9 Number/speed of nodes vs. PDR for DSR

\section{Test Case 2: End to End delay}

Figure 10 shows the variation in delay for DSR routing protocol with the change in number and speed of nodes using different mobility models (Random Waypoint, Gauss-Markov, and RGIM). The graph displays that the DSR with RGIM gives decline in delay values as compared to RWPM and GMM.

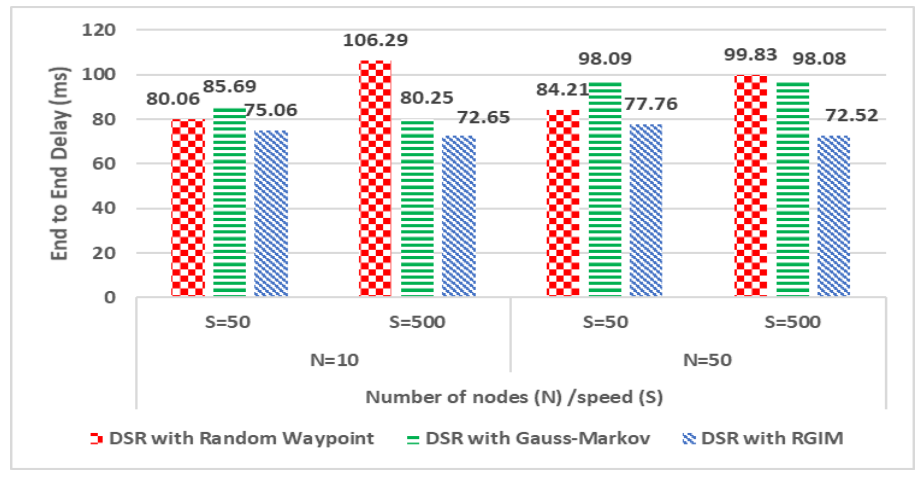

Figure 10 Number/speed of nodes vs. End to End delay for DSR

\section{Test Case 3: Throughput}

Figure 11 displays the variation of throughput of the DSR routing protocol with the change in the number of nodes and speed of nodes using different mobility models (Random Waypoint, Gauss-Markov, RGIM). From the graph, it is found that DSR with RGIM gives increase in throughput values as compared to RWPM and GMM. 


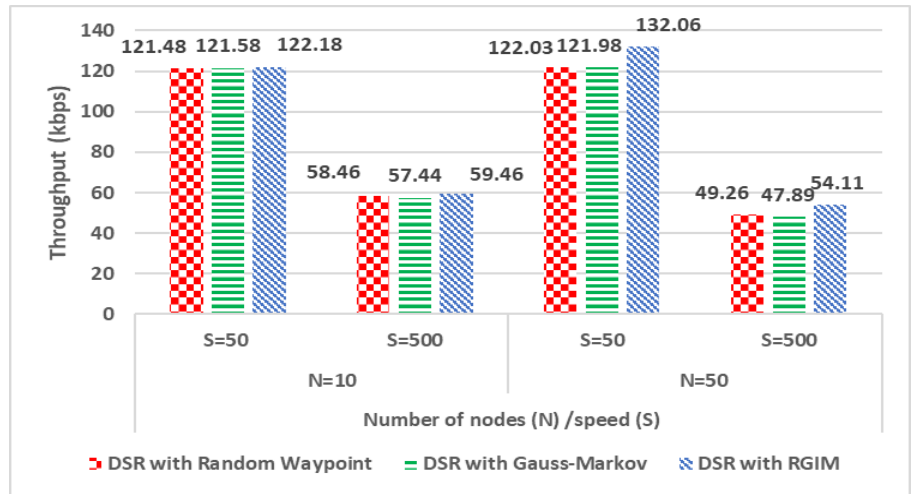

Figure 11 Number/speed of nodes vs. Throughput for DSR

\section{Test Case 4: Jitter}

Figure 12 displays the variation of jitter of the DSR routing protocol with the change in the number of nodes and speed of nodes using different mobility models (Random Waypoint, Gauss-Markov, RGIM). From the graph, it is found that DSR with RGIM gives decrease in jitter values as compared to RWPM and GMM.

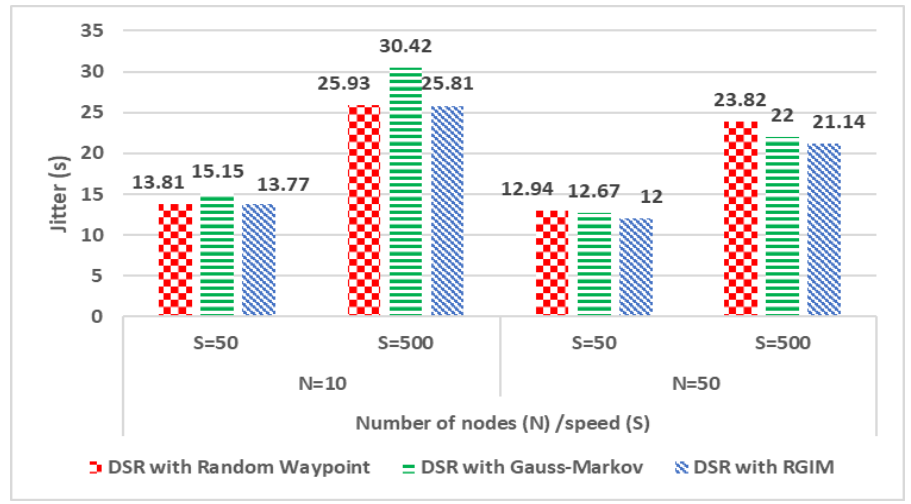

Figure 12 Number/speed of nodes vs. Jitter for DSR

\subsubsection{Simulation analysis of DSR}

From Figure 9, it is observed that for nodes equal to 10 and 50, DSR with RGIM gives increase in the packet delivery ratio compared to RWPM and GMM. At high node speed i.e. $500 \mathrm{~m} / \mathrm{s}$ and high number of nodes i.e. 50, PDR values decreases. The proposed model shows some increase in PDR as packets are delivered with less disruption in RGIM. From Figure 10, it is observed that for node count equal to 10 and 50, RGIM gives significant decline in delay values compared to RWPM and GMM. The proposed model makes a significant decrease in the delay as compared to RWPM and GMM because in RWPM and GMM the communication is difficult to handle but in RGIM communication is maintained easily. From Figure 11, it is observed that for node count equal to 10 and 50, RGIM gives more efficient throughput than RWPM and GMM. For node speed $500 \mathrm{~m} / \mathrm{s}$, there is decrease in throughput compared to low node speed. The throughput increases in RGIM as it integrates both individual models to make the model perform better in the simulation. From Figure 12, it is observed that for 10 and 50 number of 
nodes, the model RGIM shows decrease in jitter compared to RWPM and GMM. As the node speed is high i.e. 500 $\mathrm{m} / \mathrm{s}$, the jitter value increases.

\subsubsection{Simulation Results of DSDV routing protocol with different mobility models}

\section{Test Case 1: PDR}

Figure 13 displays the variation of the PDR of DSDV routing protocol with the change in the number and speed of nodes using different mobility models (Random Waypoint, Gauss-Markov, and RGIM). The graph shows that the DSDV with RGIM gives increase in packet delivery ratio values as compared to RWPM and GMM.

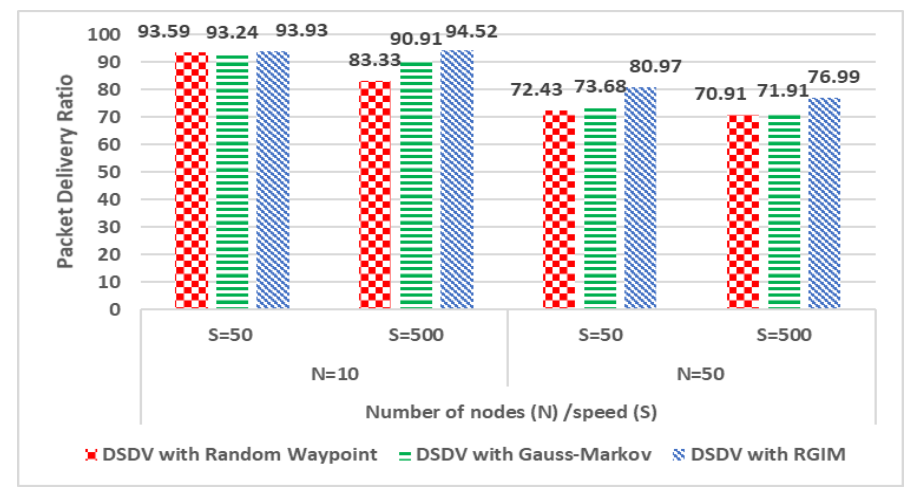

Figure 13 Number/speed of nodes vs. PDR for DSDV

\section{Test Case 2: End to End delay}

Figure 14 shows the variation in delay for DSDV routing protocol with the change in number and speed of nodes using different mobility models (Random Waypoint, Gauss-Markov, and RGIM). The graph displays that the DSDV with RGIM gives decline in delay values as compared to RWPM and GMM.

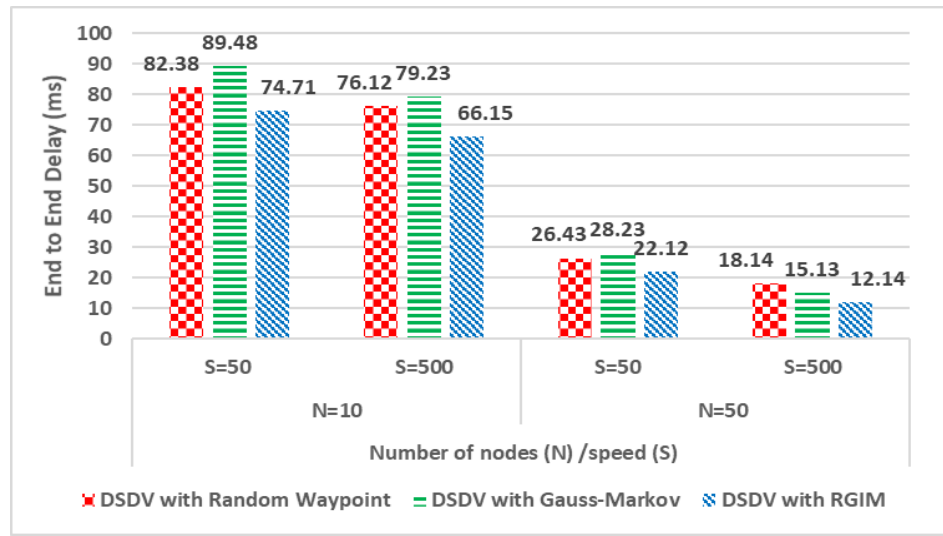

Figure 14 Number/speed of nodes vs. End to End delay for DSDV

\section{Test Case 3: Throughput}

Figure 15 displays the variation of throughput of the DSDV routing protocol with the change in the number of nodes and speed of nodes using different mobility models (Random Waypoint, Gauss-Markov, RGIM). From the graph, it is found that DSDV with RGIM gives increase in throughput values as compared to RWPM and GMM. 


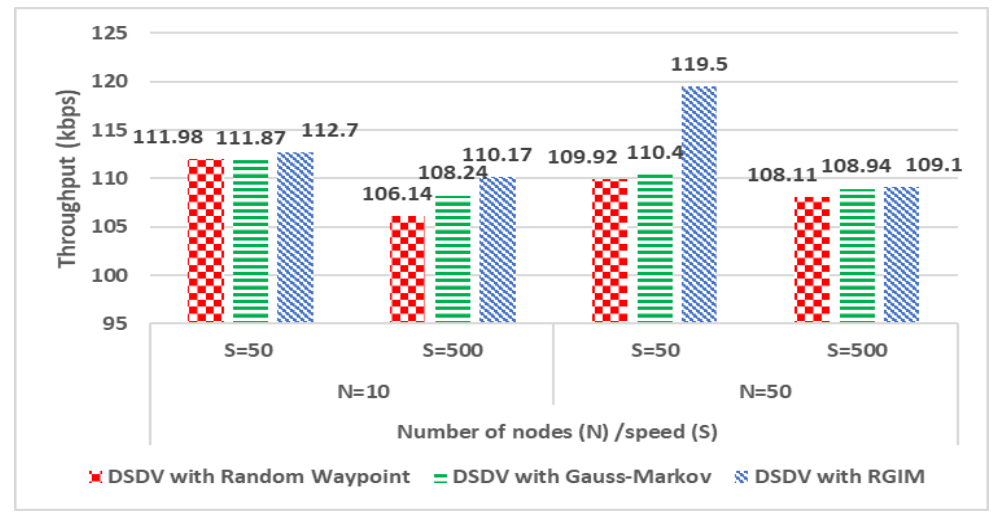

Figure 15 Number/speed of nodes vs. Throughput for DSDV

\section{Test Case 4: Jitter}

Figure 16 displays the variation of jitter of the DSDV routing protocol with the change in the number of nodes and speed of nodes using different mobility models (Random Waypoint, Gauss-Markov, RGIM). From the graph, it is found that DSDV with RGIM gives decrease in jitter values as compared to RWPM and GMM.

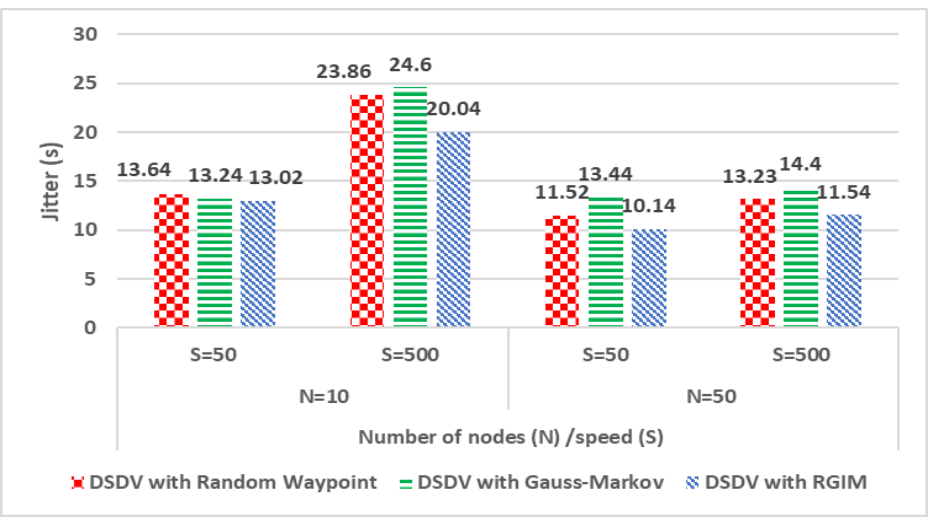

Figure 16 Number/speed of nodes vs. Jitter for DSDV

\subsubsection{Simulation analysis of DSDV}

From Figure 13, it is observed that for nodes equal to 10 and 50, DSDV with RGIM gives increase in the packet delivery ratio compared to RWPM and GMM. At node count 50 and node speed $500 \mathrm{~m} / \mathrm{s}$, PDR values decreases. From Figure 14, it is observed that for node count 50, for both low and high speed there is significant decrease in end to end delay. It shows that in DSDV with high node count, the communication is easy to maintain. RGIM shows decrease in delay compared to RWPM and GMM. From Figure 15, it is observed that for node count 10 and 50, with RGIM there is increase in throughput compared to RWPM and GMM. For high node speed i.e. $500 \mathrm{~m} / \mathrm{s}$, the value of throughput is decreasing. From Figure 16, it is observed that RGIM shows decrease in jitter for node count 10 and 50 compared to RWPM and GMM. For high node speed i.e. $500 \mathrm{~m} / \mathrm{s}$, the jitter value increases.

\subsubsection{Statistical analysis}

To validate the results, Coefficient of Variation method is used. Coefficient of variation is calculated by dividing standard deviation of observations with mean of the observations in a sample as given in equation 4. By applying 
Coefficient of variation on PDR, Throughput, Delay, and Jitter test case for validation the variation is shown in Table 3.

$$
\text { Coefficient of variation }=\frac{\text { Standard deviation }}{\text { Mean }}
$$

Test case 1: PDR

For Random Waypoint model, Coefficient of variation range is $(0.11-0.14)$ as speed of node varies from $50 \mathrm{~s}$ to $500 \mathrm{~s}$. For Gauss-Markov model, Coefficient of variation range is $(0.10-0.14)$ with respect to speed $50 \mathrm{~s}$ and $500 \mathrm{~s}$. For RGIM, Coefficient of variation range is $(0.08-0.11)$ with speed variation from $50 \mathrm{~s}$ to $500 \mathrm{~s}$.

Test case 2: Throughput

For Random Waypoint model, Coefficient of variation range is $(0.05-0.34)$ as speed of node varies from $50 \mathrm{~s}$ to $500 \mathrm{~s}$. For Gauss-Markov model, Coefficient of variation range is $(0.04-0.36)$ with respect to speed $50 \mathrm{~s}$ and $500 \mathrm{~s}$. For RGIM, Coefficient of variation range is $(0.05-0.30)$ with speed variation from $50 \mathrm{~s}$ to $500 \mathrm{~s}$.

Test case 3: Delay

For Random Waypoint model, Coefficient of variation range is $(0.32-0.48)$ as speed of node varies from $50 \mathrm{~s}$ to $500 \mathrm{~s}$. For Gauss-Markov model, Coefficient of variation range is $(0.33-0.46)$ with respect to speed $50 \mathrm{~s}$ and $500 \mathrm{~s}$. For RGIM, Coefficient of variation range is $(0.34-0.44)$ with speed variation from $50 \mathrm{~s}$ to $500 \mathrm{~s}$.

Test case 3: Jitter

For Random Waypoint model, Coefficient of variation range is $(0.07-0.25)$ as speed of node varies from $50 \mathrm{~s}$ to $500 \mathrm{~s}$. For Gauss-Markov model, Coefficient of variation range is $(0.07-0.23)$ with respect to speed $50 \mathrm{~s}$ and $500 \mathrm{~s}$. For RGIM, Coefficient of variation range is $(0.09-0.23)$ with speed variation from $50 \mathrm{~s}$ to $500 \mathrm{~s}$.

Table 3. Coefficient of variation with respect to node speed variation

\begin{tabular}{|c|c|c|c|c|c|c|c|}
\hline \multirow{2}{*}{\multicolumn{2}{|c|}{$\begin{array}{c}\text { Performance } \\
\text { Parameters }\end{array}$}} & \multicolumn{6}{|c|}{ Coefficient of Variation } \\
\hline & & \multicolumn{3}{|c|}{$\mathrm{S}=50$} & \multicolumn{3}{|c|}{$\mathrm{S}=500$} \\
\hline \multicolumn{2}{|c|}{ Test case } & $\begin{array}{c}\text { Random } \\
\text { Waypoint }\end{array}$ & $\begin{array}{l}\text { Gauss } \\
\text { Markov }\end{array}$ & RGIM & $\begin{array}{l}\text { Random } \\
\text { Waypoint }\end{array}$ & $\begin{array}{l}\text { Gauss } \\
\text { Markov }\end{array}$ & RGIM \\
\hline 1 & PDR & 0.11 & 0.10 & 0.08 & 0.14 & 0.14 & 0.11 \\
\hline 2 & Throughput & 0.05 & 0.04 & 0.05 & 0.34 & 0.36 & 0.30 \\
\hline 3 & Delay & 0.32 & 0.33 & 0.34 & 0.48 & 0.46 & 0.44 \\
\hline 4 & Jitter & 0.07 & 0.07 & 0.09 & 0.25 & 0.23 & 0.23 \\
\hline
\end{tabular}

For RGIM, the small value of Coefficient of Variation signifies that proposed model is more stable and effective as compared to Random Waypoint and Gauss-Markov model.

\subsection{Discussions and Limitations}

From the simulation analysis, it is observed that overall performance of RGIM is increased for AODV, DSR and DSDV protocols. It is because in chain model, the communication link is steady, and it will work for the long simulation duration as it incorporates both the Random Waypoint and Gauss-Markov features. Also, in chain model, the link interruption happens less as it is steadier. But when individual mobility model is used, in the Random Waypoint, with an increase in simulation duration, the speed of nodes diminishes significantly and in Gauss-Markov it is hard to deal with communication. The main finding is that RGIM model which is chain of Random Waypoint and Gauss-Markov performs best for low node speed of $50 \mathrm{~m} / \mathrm{s}$ for both 10 and 50 number of nodes. When 
compared our proposed RGIM with chain model (Random Waypoint and Manhattan Grid mobility model) by A.K. Shukla [8], for AODV having 10 nodes there is increase of $69 \mathrm{kbps}$ for throughput and increase of 9.9\% for PDR. When compared RGIM with chain model (RWP+ RPGM+ Pursue) by J. Hong and D. Zhang [31], for AODV having 50 nodes and $500 \mathrm{~m} / \mathrm{s}$ speed there is increase of $23.83 \%$ for PDR and for 50 nodes and $50 \mathrm{~m} / \mathrm{s}$ speed there is increase of $16.9 \%$ for PDR. Also, for DSDV, having 50 nodes and $500 \mathrm{~m} / \mathrm{s}$ speed there is increase of $21.55 \%$ for PDR and for 50 nodes and $50 \mathrm{~m} / \mathrm{s}$ speed there is increase of $25.97 \%$ for PDR.

When compared, throughput using RGIM for AODV having 10 nodes is 124 kbps compared to 55 kbps with chain model (Random Waypoint and Manhattan Grid mobility model) proposed by A.K. Shukla [8]. Also, PDR using RGIM model is $99.9 \%$ compared to $90 \%$ by chain model [8]. As compared to AODV using chain (RWP+RPGM) proposed by J. Hong and D. Zhang [32] which gives $74.94 \%$ PDR for 50 nodes and 500 speed, RGIM model gives 98.77\% PDR. For AODV having 50 speed and 50 nodes chain model [32] gives 83\% PDR, RGIM gives 99.9\% PDR. For DSDV, having 50 nodes and 500 speed chain model [32] gives $55.44 \%$ PDR, RGIM gives 76.99\% PDR. For DSDV, having 50 nodes and 50 speed chain model [32] gives 55\% PDR, RGIM gives $80.97 \%$ PDR. The limitation is observed for high node speed of $500 \mathrm{~m} / \mathrm{s}$, as it results in low performance. It is because the topology is highly affected by high node speed.

\section{Conclusions and Future Scope}

In this paper, Chain mobility model using existing Random Waypoint mobility model and Gauss-Markov mobility model is proposed for flying ad-hoc network. It integrates Random Waypoint and Gauss-Markov and gives an effective improvement in various QoS parameters. The proposed model, i.e. RGIM, has been simulated using the NS2 simulator. Using RGIM different mobility scenarios are developed by varying number of nodes and speed of nodes. The routing protocols AODV, DSR and DSDV are experimentally analyzed for various performance parameters, i.e. packet delivery ratio, the end to end delay, jitter and throughput by using these generated mobility scenarios. From the simulation results, it is observed that AODV, DSR and DSDV protocol with RGIM gives less end to end delay, more packet delivery ratio, less jitter and better throughput than with the Random Waypoint mobility model and Gauss-Markov mobility model. So, it is concluded that RGIM gives better performance for routing protocols as compared to Random Waypoint and Gauss-Markov model applied individually.

In this research work, RGIM is applied only to evaluate the performance of AODV, DSR and DSDV routing protocols. In future, other reactive or proactive routing protocol's performance can be evaluated using the proposed chain model i.e. RGIM. Also, the chain model can be varied by using a combination of some different existing mobility models to get better results.

\section{Acknowledgments}

We would like to thank the editor, area editor and anonymous reviewers for their valuable comments and suggestions to help and improve our research paper.

\section{References}

[1] Bekmezci, I., Sahingoz, O.K., Temel, Ş. (2013) Flying Ad-Hoc Networks (FANETs): A survey. Ad Hoc Networks, 11, 12541270 .

[2] Ryan, A., Zennaro, M., Howell, A., Sengupta, R., Hedrick, J. (2004) An overview of emerging results in cooperative UAV control. In: 2004 43rd IEEE Conference on Decision and Control, Nassau, Bahamas, 14-17 December, pp. 602-607. IEEE.

[3] Hayat, S., Yanmaz, E., Muzaffar, R. (2016) Survey on Unmanned Aerial Vehicle Networks for Civil Applications: A Communications Viewpoint. IEEE Communications Surveys \& Tutorials, 18, 2624-2661.

[4] Erdelj, M., Natalizio, E., Chowdhury, K.R., Akyildiz, I.F. (2017) Help from the Sky: Leveraging UAVs for Disaster Management. IEEE Pervasive Computing, 16 , 24-32 
[5] Kaur P., Singh A. (2018) Nature-Inspired Optimization Techniques in VANETs and FANETs: A Survey. In Bhattacharyya S., Chaki N., Konar D., Chakraborty U., Singh C. (eds), Advanced Computational and Communication Paradigms. Advances in Intelligent Systems and Computing (AISC) Book Series, Springer, Singapore.

[6] Oubbati, O.S., Lakas, A., Zhou, F., Güneş, M., Yagoubi, M.B. (2017) A survey on position-based routing protocols for Flying Ad hoc Networks (FANETs). Vehicular Communications, 10, 29-56.

[7] Bhasin, A., Kumar, D. (2012) Performance Analysis of Reactive Routing Protocols in Chain Mobility Models. International Journal of Computer Science and Communication, 3, 199-201.

[8] Shukla, A.K., Jha, C.K. (2014) Simulation based Assessment of Realistic Mobility Pattern in Ad Hoc Networks. International Journal of Computer Applications (IJCA), 5-9, 2014.

[9] Leonov, A. (2016) Modeling of bio-inspired algorithms AntHocNet and BeeAdHoc for Flying Ad Hoc Networks (FANETS). In: 2016 13th International Scientific-Technical Conference on Actual Problems of Electronics Instrument Engineering (APEIE), Novosibirsk, Russia, 3-6 October, pp. 90-99. IEEE.

[10] Biomo, J.-D.M.M., Kunz, T., St-Hilaire, M. (2014) Routing in unmanned aerial ad hoc networks: A recovery strategy for Greedy geographic forwarding failure. In: 2014 IEEE Wireless Communications and Networking Conference (WCNC), Istanbul, Turkey, 6-9 April, pp. 2236-2241. IEEE.

[11] Biomo, J.-D.M.M., Kunz, T., St-Hilaire, M. (2014) An enhanced Gauss-Markov mobility model for simulations of unmanned aerial ad hoc networks. In: 2014 7th IFIP Wireless and Mobile Networking Conference (WMNC), Vilamoura, Portugal, 20-22 May, pp. 1-8. IEEE.

[12] Lin L., Sun Q., Li J., Yang F. (2012) A novel geographic position mobility oriented routing strategy for UAVs. Journal of Computational Information Systems, 8, 709-716.

[13] A Mobility Scenario Generation and Analysis Tool, Documentation. University of Osnabruck, (2016). Accessed 19 Sep 2017.

[14] NETWORK SIMULATOR, NS2 DIRECTORY AND LANGUAGES, http://www.ns2blogger.in/p/n.html. Accessed 20 Oct 2017.

[15] Sharma, P., Yadav, I. (2016) Improving Reactive Greedy Reactive Routing in Flying Ad Hoc Networks. International Journal of Science, Engineering and Technology Research (IJSETR), 5, 2276-2281.

[16] Gankhuyag, G., Shrestha, A.P., Yoo, S.-J. (2016) A novel directional routing scheme for flying ad-hoc networks. In: 2016 International Conference on Information and Communication Technology Convergence (ICTC), Jeju, South Korea, 19-21 October, pp. 593-597. IEEE.

[17] Gupta, P., Gupta S. (2013) Performance Evaluation of MANET Routing Protocols in Random Waypoint Mobility Model. In: IJCA Proceedings on International Conference and Workshop on Emerging Trends in Technology 2013 ICWET. pp. 25-30, 2013.

[18] Kout, A., Labed, S., Chikhi, S., Bourennane, E.B. (2017) AODVCS, a new bio-inspired routing protocol based on cuckoo search algorithm for mobile ad hoc networks. Wireless Networks, 24, 2509-2519.

[19] Zheng, Z., Sangaiah, A.K., Wang, T. (2018) Adaptive Communication Protocols in Flying Ad Hoc Network. IEEE Communications Magazine, 56, 136-142.

[20] Gankhuyag, G., Shrestha, A.P., Yoo, S.-J. (2017) Robust and Reliable Predictive Routing Strategy for Flying Ad-Hoc Networks. IEEE Access, 5, 643-654. 
[21] Chenghao, D. (2015) An improved routing protocol based on Gauss-Markov model in Ad Hoc networks utilizing prediction of link quality. In: 2015 34th Chinese Control Conference (CCC), Hangzhou, China, 28-30 July, pp. 6507-6511. IEEE.

[22] Alenazi, M., Sahin, C., Sterbenz, J.P. (2012) Design Improvement and Implementation of 3D Gauss-Markov Mobility Model. International Telemetering Conference Proceedings, Volume 48 (2012)

[23] Jung, W.-S., Yim, J., Ko, Y.-B. (2017) QGeo: Q-Learning-Based Geographic Ad HocRouting Protocol for Unmanned Robotic Networks. IEEE Communications Letters, 21, 2258-2261.

[24] Wang, W., Guan, X., Wang, B., Wang, Y. (2010) A novel mobility model based on semi-random circular movement in mobile ad hoc networks. Information Sciences. 180, 399-413.

[25] Bahloul, N.E.H., Boudjit, S., Abdennebi, M., Boubiche, D.E. 2018 A Flocking-Based on Demand Routing Protocol for Unmanned Aerial Vehicles. Journal of Computer Science and Technology, 33, 263-276.

[26] Huan, Y., Hong, J., Lei, L. (2008) Performance analysis of mobility models in sparse Ad-hoc networks. In: 2008 27th Chinese Control Conference, Kunming, China, 16-18 July, pp. 216-220, IEEE.

[27] Bekmezci, I., Ermis M., Kaplan S. (2014) Connected multi UAV task planning for Flying Ad Hoc Networks. In: 2014 IEEE International Black Sea Conference on Communications and Networking (BlackSeaCom), Odessa, Ukraine, 27-30 May, pp. 28-32, IEEE.

[28] Bettstetter, C., Hartenstein, H., Pérez-Costa, X. (2004) Stochastic Properties of the Random Waypoint Mobility Model. Wireless Networks, 10, 555-567.

[29] Kumari, K., Sah, B., Maakar, S. (2015) A Survey: Different Mobility Model for FANET. International Journal of Advanced Research in Computer Science and Software Engineering, 5, 1170-1173.

[30] Broyles, D., Jabbar, A. (2010) Design and Analysis of a 3-D Gauss-Markov Model for Highly Dynamic Airborne Networks. In: International Telemetering Conference (ITC 2010), San Diego, CA, pp. 25-28.

[31] Yang, H., Liu, Z. (2019) An optimization routing protocol for FANETs. EURASIP Journal on Wireless Communications and Networking, 1,120.

[32] Hong, J., Zhang, D., (2019) TARCS: A Topology Change Aware-Based Routing Protocol Choosing Scheme of FANETs. Electronics, 8, 274.

[33] H. Yang, Z. Li, Z. Liu (2019). A method of routing optimization using CHNN in MANET. Journal of Ambient Intelligence and Humanized Computing, 10(5), 1759-1768.

[34] H. Yang, Z. Li, Z. Liu, Neural networks for MANET AODV: an optimization approach. Clust. Comput. 20(4), 3369-3377 (2017)

[35] Zhang, D., Yang, Z., Raychoudhury, V., Chen, Z., \& Lloret, J. (2013). An energy-efficient routing protocol using movement trends in vehicular ad hoc networks. The Computer Journal, 56(8), 938-946.

[36] Boonma, Pruet, and Junichi Suzuki. "Moppet: A model-driven performance engineering framework for wireless sensor networks." The Computer Journal 53, no. 10 (2010): 1674-1690. 